\title{
DESMONTANDO MITOS SOBRE LA TIERRA EN LA EDAD MEDIA
}

\author{
Sandra Sáenz-López Pérez
}

Universidad Autónoma de Madrid

\section{RESUMEN}

Este trabajo desmonta, gracias a la cartografía, tres mitos comúnmente asociados a la Edad Media: la idea de que la Tierra se concebía plana, que Jerusalén se ubicaba en el centro del mundo, y que en los confines habitaban los dragones. La riqueza visual de la que hacen alarde los mapas del Medievo presenta un mundo más complejo que el que le hemos inventado. Como es bien sabido, las apariencias engañan. La falta de proyección científica y el peso del simbolismo religioso deben ser superados para conseguir, con ello, descubrir el mundo de la Edad Media.

Palabras clave: Medievo, cartografía, planitud, Jerusalén, monstruos.

\section{DISMANTLING MYTHS ABOUT THE EARTH \\ IN THE MIDDLE AGES}

\section{Abstract}

This paper dismantles thanks to cartography three myths commonly associated with the Middle Ages: the idea that the Earth was flat, that Jerusalem was in the center of the world, and that dragons inhabited its margins. The visual richness that medieval maps boast presents a more complex world than the one we have invented for it. As it is well known, appearances can be deceiving. The lack of scientific projection and the importance of religious symbolism must be overcome to discover the world of the Middle Ages.

KEYwords: Middle ages, cartography, flatness, Jerusalem, monsters. 
Los diez siglos que comprenden el espacio de tiempo entre la caída del Imperio Romano de Occidente en el 476 d.C. y la llegada de Cristóbal Colón al Nuevo Mundo en 1492 -márgenes cronológicos comúnmente aceptados para delimitar lo que se ha venido en llamar la "Edad Media»- fueron considerados durante unos cuantos siglos más una época de barbarie cultural y de oscurantismo religioso; ya en sí el nombre con el que aún se conoce es indicativo de abarcar una época intermedia entre dos cumbres de la luminosa civilización: la Antigüedad clásica y su Renacimiento ${ }^{1}$. Pese a los momentos históricos en los que surgió el interés por mirar a la Edad Media -a la cabeza de todos el Romanticismo decimonónico-, esa densa sombra que se arrojó sobre el Medievo sigue pesando, incluso tras brillantes esfuerzos por demostrar que esa época estaba llena de luz, en todos los sentidos: simbólico, material e intelectual ${ }^{2}$. Pensar en la Edad Media supone aún hoy llenarla de ignorancia, misoginia, intolerancia, y de otra serie de adjetivaciones de carácter peyorativo. Este trabajo no pretende -aunque bien lo quisiera su autora- acabar con estas ideas. Tan solo nos conformaremos con contribuir a corregir algunas de ellas, concretamente a desmontar tres mitos sobre la imagen que, según se dice, el hombre de la Edad Media tenía del mundo. Y para ello qué mejor que servirnos de representaciones cartográficas.

\section{LA TIERRA ES PLANA}

Cuantitativamente la mayoría de los mapas realizados en la Edad Media representan la Tierra de forma circular: desde los llamados mapas esquemáticos tripartitos que exhiben las tres partes del mundo conocidas, evocando su reparto entre los hijos de Noé tras el diluvio universal (fig. 1), a los mapas historiados que, pese a una mayor complejidad en la geografía física, mantienen el círculo para el dibujo de su contorno (por ejemplo, figs. 12 y 13). La forma circular debió de ser igualmente habitual en las cartografías antiguas. Ya está presente en el llamado mapamundi babilónico (ca. 600 a.C.) $)^{3}$, el más antiguo conservado: inciso en una tablilla de arcilla, el océano abraza la Tierra a modo de anillo y la separa de las míticas regiones en las que reina la oscuridad, representadas a base de triángulos. La forma circular pervivió en la tradición cartográfica clásica a juzgar por las críticas que Heródoto (siglo v a.C.) lanzaba en su Historia (Iv, 36): «Me da risa ver que haya habido muchos que han trazado mapas del mundo sin que ninguno los haya comentado detallada y sensatamente: representan un Océano que, con su curso, rodea la tie-

${ }_{1}$ Para una puesta al día de las formas que dieron nombre a esta época de la historia véase E. Baura García, «De la "media tempestas" al "medium aevum”. La aparición de los diferentes nombres de la Edad Media». Estudios Medievales Hispánicos, 2 (2013), pp. 27-46.

${ }^{2}$ Sirvan como ejemplo los trabajos de J. Le Goff, La civilización del Occidente medieval. Barcelona, Paidós, 1999; y Una larga Edad Media. Barcelona, Paidós, 2008.

${ }_{3}$ British Museum, Londres (BM 92687). Para una aproximación al mapa véase C. UlKeкuL, An 8,200 year old map. The Town Plan of Çatalhöyük. Cağaloğlu, Dönence, 1999. 


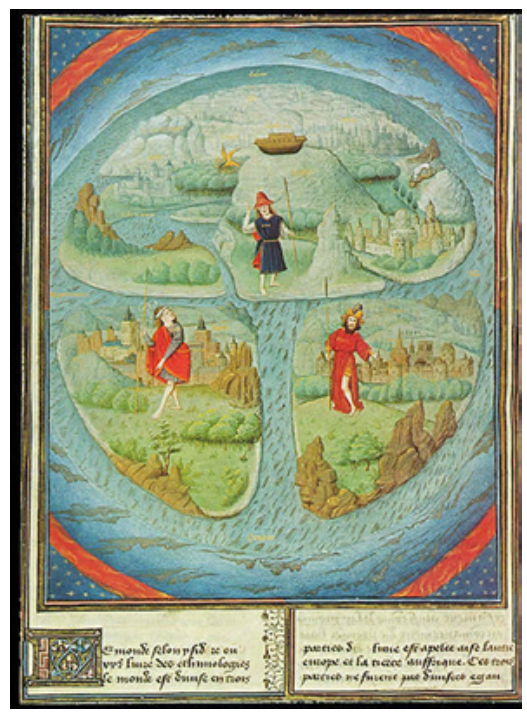

Fig. 1. Jean Mansel, La Fleur des Histoires (1459-1463). Bibliothèque

Royale de Belgique, Bruselas

(Ms. 9231, fol. 281v).

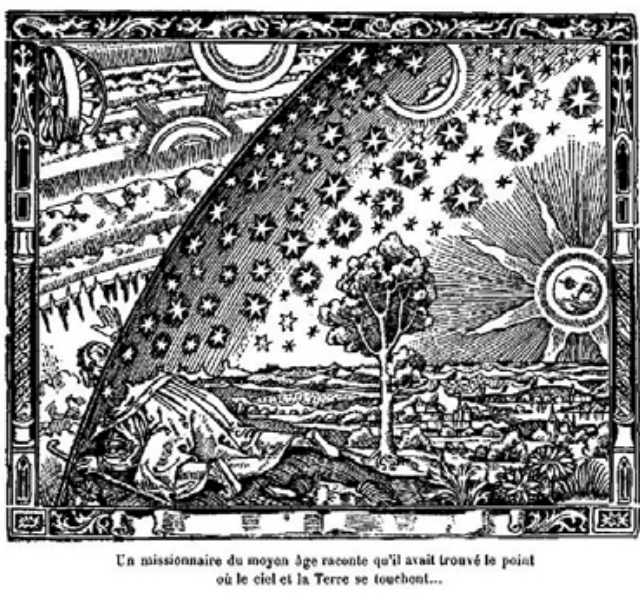

Fig. 2. Camille Flammarion, L'Atmosphere: Météorologie Populaire. París, Hachette, 1888, p. 163.

rra -que según ellos, es circular, como si estuviese hecha con un compás-y dan las mismas dimensiones a Asia que a Europa ${ }^{4} »$.

Los mapas circulares son los más comunes de la cartografía altomedieval y los más antiguos conservados responden a esta forma, pero también son frecuentes durante toda la Baja Edad Media: de hecho, el primer mapa impreso fue un mapamundi tripartito de «T en $\mathrm{O}$ » incluido en las Etimologías de san Isidoro (Augsburgo: Günther Zainer, 1472). La forma circular invita a imaginar la Tierra en el Medievo como un disco plano, rodeada de un océano anular, más allá del cual se extendía el abismo. Al menos así imaginaron que imaginaba el mundo el hombre medieval con posterioridad a esa época. La representación que más ha contribuido taladrar esa idea en nuestra retina figura dentro de L'Atmosphere: Météorologie Populaire de Camille Flammarion publicada en 1888, que muestra, tal como indica el pie de foto de esa publicación, que un misionero de la Edad Media cuenta que había encontrado el lugar en el que el Cielo y la Tierra se encontraban (fig. 2). El personaje en cuestión había alcanzado los extremos de una Tierra circular plana y atravesaba con su cabeza y manos la bóveda celeste estrellada, quizá una evocación de la octava esfera,

\footnotetext{
${ }^{4}$ Heródoto, Historia. Madrid, Editorial Gredos, 1977, pp. 316-317.
} 


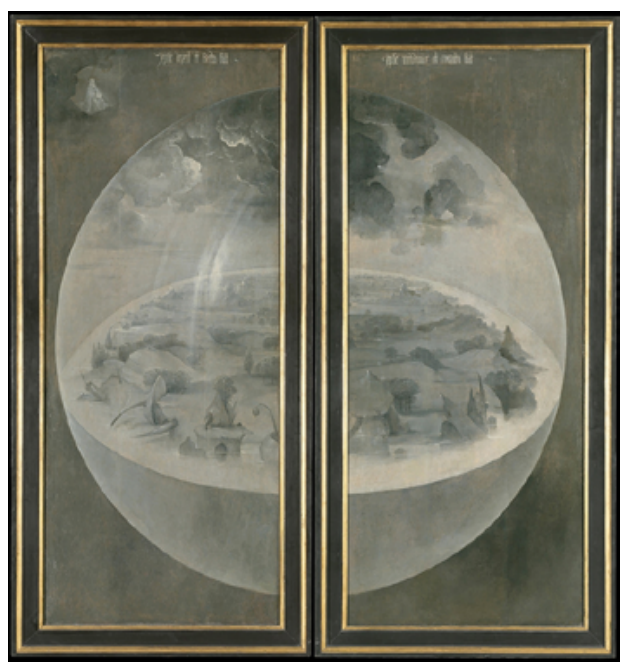

Fig. 3. El Bosco, Triptico del Jardín de las delicias (1490-1500). Museo Nacional del Prado, Madrid (n. ${ }^{\circ}$ cat. P002823).

la más exterior de todas, llamada también esfera de las estrellas fijas ${ }^{5}$; más allá se extiende un universo con su maquinaria cósmica, también supuestamente medieval.

De todas las referencias icónicas que se asemejan a la de Camille Flammarion la más próxima es indudablemente aquella con la que El Bosco cierra su afamado Jardín de las delicias (1490-1500) ${ }^{6}$. El tríptico cerrado muestra el tercer día de la creación del mundo, y en la parte superior izquierda, entronizado entre nubes, Dios Padre contempla su obra (fig. 3). Toda ella está contenida dentro de una esfera de cristal, brillante y transparente, símbolo de la fragilidad de las cosas caducas ${ }^{7}$ o idea, también evocada por Flammarion, del universo medieval rodeado de una esfera cristalina. En su interior, siguiendo las sagradas escrituras, las aguas se han separado de la tierra y desplazado al borde, adoptando así el tradicional aspecto de anillo circundante; lo seco, por su parte, parece flotar a modo de disco. Esta obra se ha descrito como «la tierra - plana, con agua alrededor y con abundante vegetación, reconocible o no [...] de acuerdo con las convenciones de la época» ${ }^{8}$. En cualquier

5 Para el universo medieval véase M. Aguiar Aguilar, «Modelos cosmológicos medievales». Revista de Filología de la Universidad de La Laguna, núm. 14 (1995), pp. 7-15, esp. 9.

${ }^{6}$ Museo Nacional del Prado, Madrid (n. ${ }^{\circ}$ cat. P002823). Dentro de la extensa bibliografía producida en torno a esta obra véanse M.P. Silva Maroto, «El Bosco. Tríptico del Jardín de las delicias», en El Bosco. La exposición del V Centenario, Madrid, Museo Nacional del Prado, 2016, pp. 330-346; y R.L. Falkenburg, Le Jardin des Délices. París, Hazan, 2015.

7 C. De Tolnay, Hieronymus Bosch. Bâle, Les Éditions Holbein, 1937, p. 33.

8 M.P. Silva Maroto, Pintura flamenca de los siglos XV y XVI: guía. Madrid, Museo del Prado, 2001, p. 162. 


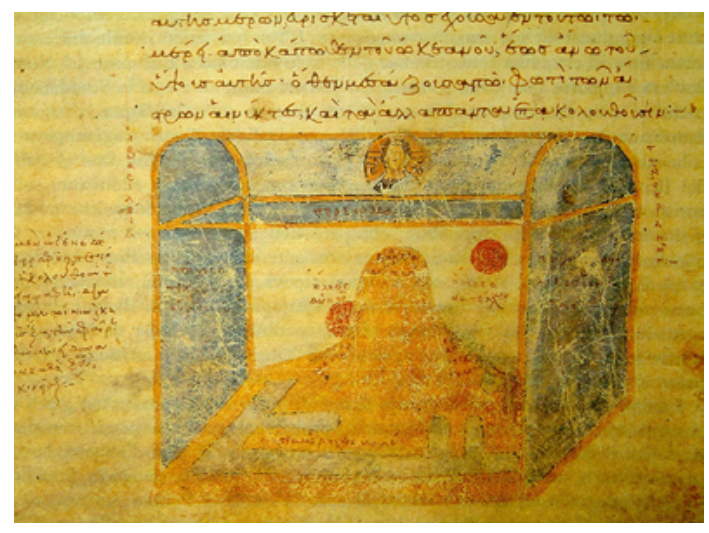

Fig. 4. Cosmas Indicopleustes, Topographia Christiana (siglo XI). Biblioteca Medicea Laurenziana, Florencia (Ms. 9.28, fol. 95v).

caso, el pintor flamenco no puede significarse como un artista medieval. Retomaremos esta obra más adelante.

Pese a los ríos de tinta que se han vertido sobre la planitud de la Tierra en la Edad Media, numerosas voces de ese momento se esforzaron por demostrar gráfica y textualmente su esfericidad ${ }^{9}$. También hubo quienes, por el contrario, se aferraron a los textos sagrados y defendieron la idea plana. Así lo hicieron Latancio (ca. 250ca. 325), apologista cristiano de origen norteafricano, en sus Divinae Institutiones (III, 24), o Cosmas Indicopleustes (siglo vi), mercader, teólogo y geógrafo bizantino, en Topographia Christiana ${ }^{10}$. Cabe ahora preguntarse ;cómo explicar ante una Tierra plana realidades tan evidentes como la sucesión del día y la noche? Cosmas Indicopleustes lo hizo con la existencia de una gran montaña al noroeste del mundo detrás de la cual se ocultan, alternativamente, el sol y la luna (Libro Iv, 188-189), idea que transfirió a la imagen del universo (fig. 4). Lactancio y Cosmas Indicopleustes son

${ }^{9}$ Más numerosa es aún la literatura académica que ha probado la noción de la Tierra esférica en el Medievo desde muy diversas aproximaciones y recurriendo a distintas fuentes; véanse para una aproximación al tema L.B. CorMACK, "That Medieval Christians Taught that the Earth was Flat», en R.L. Numbers (eds.), Galileo Goes to Jail and Other Myths About Science and Religion, Cambridge, MA, Harvard University Press, 2009, pp. 28-34; y L.M. Bishop, «The Myth of the Flat Earth», en S. Harris y B.L. Grigsby (eds.), Misconceptions about the Middle Ages. Routledge Studies in Medieval Religion and Culture, Londres-Nueva York, Routledge, 2008, pp. 97-101.

${ }^{10}$ Para la imagen de la Tierra según este último autor véase W. Wolska-Conus, "Cosmas Indicopleustès et la figure de la terre», en Moïse géographe. Recherches sur les représentations juives et chrétiennes de l'espace, París, Libraire Philosophique J. Vrin, 1988, pp. 79-98; y M. Kominko, The World of Kosmas: Illustrated Byzantine Codices of the Christian Topography. Nueva York, Cambridge University Press, 2013. 


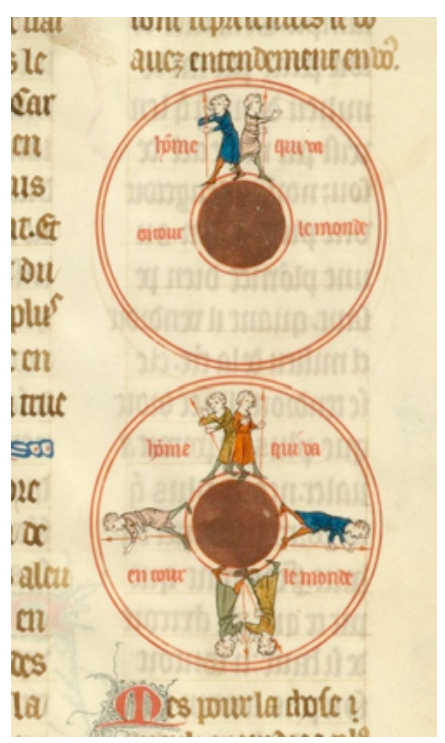

Fig. 5. Gossuin de Metz, Image du monde (1340-1350). Bibliothèque nationale de France, París (Ms. Français 25344, fol. 39v).

en cualquier caso excepciones que confirman la regla de la esfericidad de la Tierra medieval. Debemos dar ahora paso a quienes así lo explicaron.

El poeta francés Gossuin de Metz (siglo XIII) afirmaba en su Image du monde que «la Tierra es redonda, y si no hubiera obstáculos, un hombre podría recorrerla, como una mosca circula alrededor de una manzana; dos hombres podrían separarse, marchando en direcciones opuestas, uno hacia el Este, otro hacia el Oeste, de forma que se reencontrarían en las antípodas ${ }^{\prime 1}$.

Numerosos ejemplares manuscritos de esta obra están iluminados y exhiben ese hipotético viaje alrededor del mundo, demostrando gráficamente la esfericidad de la Tierra (fig. 5). Siguiendo ese pasaje se incorporan dos esferas, una sobre otra, disponiendo en la superior a los viajeros en el mismo extremo, dispuestos a lanzarse en direcciones opuestas, y en la inferior el viaje completo hasta llegar al reencuentro en las antípodas. De manera semejante, debemos asimismo recordar las palabras del monje franciscano, también de origen francés, Matfré Ermengaud (fl. 1288-1322), quien afirma en su Le breviari d'amor, compuesto entre 1288 y 1292: «El agua del mar ciñe y cubre la Tierra por todas partes excepto por una, que Dios nos dejó para

11 Traducción a partir de la edición francesa de O.H. Prior (ed.), L'image du monde de mâेtre Gossouin. Rédaction en prose. Texte du manuscrit de la Bibliothèque nationale, fonds français No. 574 , avec corrections d'après d'autres manuscrits, Lausana-París, Librairie Payot \& Cie., 1913, pp. 93-94. 




Fig. 6. Matfré Ermengaud, Le breviari d'amor (siglo xIv).

Biblioteca Nacional de España, Madrid (Mss/Res. 203, fol. 37r).

que podamos habitar en ella. Y, en comparación, la parte que el agua deja al descubierto es muy pequeña, tan pequeña como lo que sobresaldría de una manzana metida en el agua. Y la parte de la tierra tiene venas de agua que la atraviesan, pues de otro modo se secaría en exceso y se convertiría en polvo» ${ }^{12}$.

Los manuscritos iluminados de esta obra, como el ejemplar del siglo XIV de la Biblioteca Nacional de España, ilustran este pasaje a través de una esfera menor, la Tierra, que flota sobre otra mayor y externa, la gran masa de agua (fig. 6) ${ }^{13}$. En esta imagen se evoca el agua a través del dibujo convencional de la línea ondulada, tanto para la esfera más externa como para el elemento hídrico terrestre-esas «venas de agua» que describe el texto-.

A partir de las imágenes de Le breviari d'amor podemos reconstruir el cosmos geocéntrico medieval y movernos hacia imágenes científicas como las conteni-

12 A. Ferrando y V. Martines, «Traducción», en Breviari d'amor de Matfre Ermengaud: (Biblioteca Nacional de Rusia, Isp. F.v. XIV.N1): libro de estudios, San Petersburgo, Biblioteca Nacional de Rusia-Madrid, A y N Ediciones, 2007, p. 295.

${ }^{13}$ Biblioteca Nacional de España, Madrid (BNE/MSS/Res. 203). Para este manuscrito véase C. Miranda García-Tejedor, «Los manuscritos con pinturas del Breviari d'amor de Matfre Ermengaud de Béziers. Un estado de la cuestión", en J. Yarza Luaces, La miniatura medieval en la Peninsula Ibérica, Murcia, Nausícaä, 2007, pp. 313-373; e idem, "Iconografía del 'Breviari d'amor'. Escorial, Ms. S.I.3, Madrid, Biblioteca Nacional, Ms. Res. 203», tesis doctoral, 4 vols. Madrid, Universidad Complutense de Madrid, 2002, vol. 1, pp. 463-465. Este manuscrito ha sido reproducido en facsímil en M. Ermengaud, Breviari d'amor. Valenciano. Valencia, Vicent García Editores, 1980. 


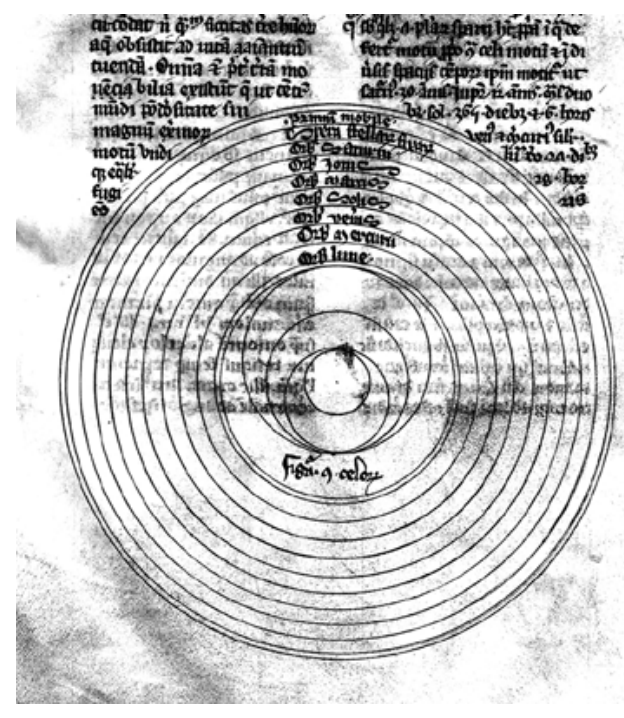

Fig. 7. Johannes de Sacrobosco, Sphera (finales del siglo XIV). Biblioteca de la Universidad de Salamanca (Ms. 2662, fol. 8v).

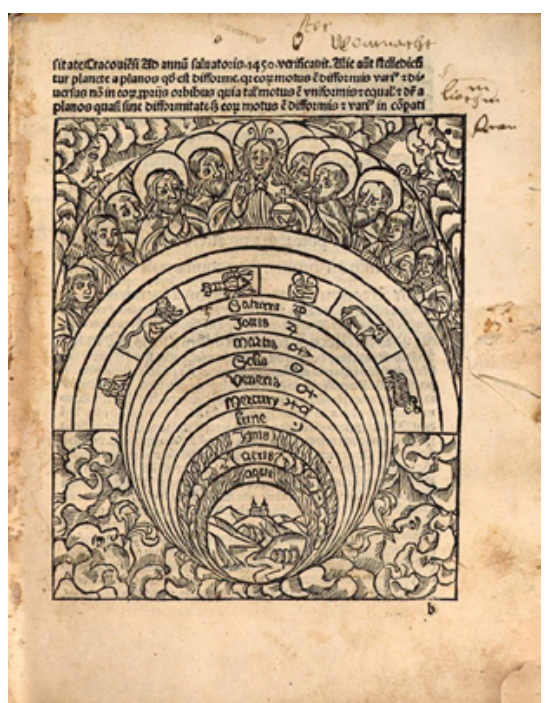

Fig. 8. Juan de Glogovia, Introductorium compendiosum in tractatum sphere material. Joa. de Sacrobusto (Cracovia, 1506). Bayerische Staatsbibliothek, Múnich (Res/4 A.gr.b. 430).

das en las muchas ediciones que emanaron de la Esfera (ca. 1230) de Johannes de Sacrobosco ${ }^{14}$, por ejemplo, la copia manuscrita de finales del siglo XIV de la Biblioteca de la Universidad de Salamanca (Ms. 2662, fol. 8v). La Tierra ocupa el núcleo más interno del cosmos y está rodeada de otros cielos o esferas (fig. 7). En primer lugar, en el mundo sublunar, se suceden el Agua, el Aire y el Fuego, conformando junto con la Tierra los cuatro elementos clásicos de la Naturaleza. Más allá se localizan los planetas: Luna, Mercurio, Venus, Sol, Marte, Júpiter y Saturno. A continuación, la octava esfera o esfera de las estrellas fijas, ya mencionada anteriormente, y rodeándola el primum mobile o primer móvil, a partir del cual Dios pone en marcha la maquinaria del universo generando un movimiento que se propaga hasta la Luna. La divinidad habita en el Empíreo, la esfera más externa, perfecta e inmutable, como figura en otro ejemplar derivado de la Esfera de Sacrobosco, en este caso con los comentarios del humanista polaco Juan de Glogovia, impreso en Cracovia en 1506 (fig. 8).

14 Sigue siendo de consulta obligada para Sacrobosco y su obra el trabajo de O. Pedersen, "In quest of Sacrobosco». Journal for the History of Astronomy, 16 (1985), pp. 175-221. 


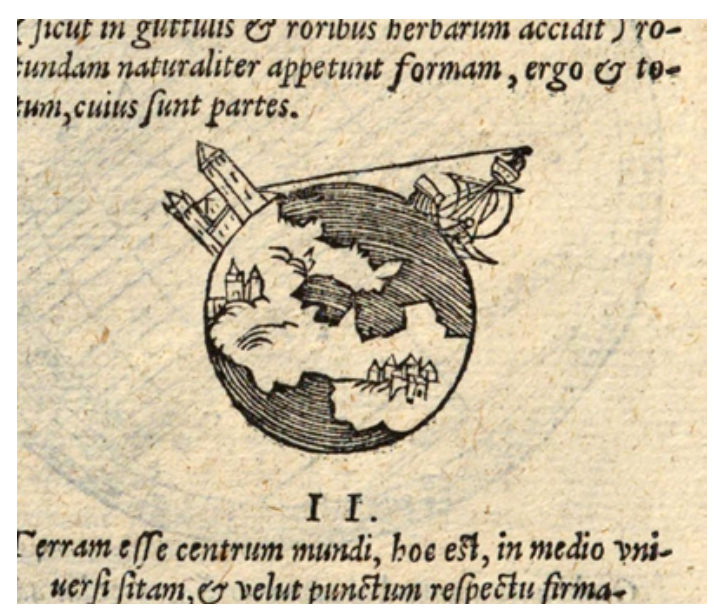

Fig. 9. Jean Richard, Sphaera Iohannis De Sacrobosco (Amberes, 1547). Staats- und Stadtbibliothek, Augsburg (Math 747).

Dentro de la literatura científica la Esfera del afamado astrónomo es sin duda paradigmática para explicar que la Tierra es redonda. En muchas partes de este tratado se describen las razones de esta redondez. Citaremos para este caso extractos traducidos al castellano a partir de la edición latina impresa en Amberes en 1547 por Jean Richard. La descripción de la Tierra comienza afirmando: "Que la tierra es redonda así se prueba: los signos y las estrellas no salen y se ocultan igualmente para todos los hombres, en dondequiera que se encuentren; sino que primero salen y se ocultan para aquéllos que están hacia el oriente» ${ }^{15}$. Además de razones astronómicas, pesan en el razonamiento otras de índole práctica, demostradas por la propia experiencia náutica:

Póngase una seńal en la orilla del mar y salga una nave del puerto, y conforme se aleje, el ojo del que está al pie del mástil no puede ver la señal, estando en la nave; el ojo del que está en lo más alto del mástil verá bien aquella señal. Pero el ojo del que está junto al pie del mástil, debiera ver mejor la señal, que el que está sobre la punta del mástil, como aparece por las líneas trazadas de uno y otro a la señal, y ninguna otra causa hay de esto que el tumor del agua. Exclúyanse todos los otros impedimentos como las nubes y los vapores que suben ${ }^{16}$.

Este experimento está además explicado gráficamente gracias a esquemáticos grabados que Jean Richard incorporó también en otras ediciones de Sacrobosco (fig. 9).

${ }^{15}$ J.P. Guzmán de Alba, La Esfera de Juan de Sacrobosco. Potes, Museo Cartográfico «Juan de la Cosa», 2019, p. 24.

16 Ibidem. 
Sirva además esta obra para testimoniar que pocas décadas antes de que El Bosco pintase su Tríptico del Jardín de las Delicias, la Tierra se sabía -o se seguía sabiendoesférica. Volvemos pues a esta hipnótica obra maestra del Prado, a la que no debiéramos tratar de buscar enigmáticas explicaciones, pues como afirmó Hans Belting bien pudiera responder tan solo al reflejo de una utopía ${ }^{17}$. ¿Cómo explicar esa contradictoria imagen a medio camino entre la esfera y la planitud? Para Claude Kappler, «la ambigüedad de esta figura proviene de la necesidad de representar una superficie terrestre plana, tal como la vivimos cotidianamente, sin pasar por representaciones geométricas abstractas, y de la necesidad también, sin embargo, de dar una idea de la esfericidad del universo" ${ }^{18}$.

Con El Bosco y Sacrobosco ponemos fin a un viaje que nos ha llevado a rastrear en fuentes de la Baja Edad Media y la temprana Edad Moderna distintos esfuerzos por demostrar que el mundo se sabía redondo. Cabe ahora preguntarse ¿desde cuándo era así conocido? La esfericidad de la Tierra fue primeramente descrita por Pitágoras (siglo vi a.C.) según testimonio de Diógenes Laercio (siglo III d.C.), quien en su Vidas, opiniones y sentencias de los filósofos más ilustres (VIII, 15) afirma:

Alejandro en las Sucesiones de los filósofos dice haber hallado en los escritos Pitagóricos también las cosas siguientes: [...] los cuerpos sólidos, de los cuales constan los cuatro elementos, fuego, agua, tierra y aire, que trascienden y giran por todas las cosas, y de ellos se engendra el mundo animado, intelectual, esférico, que abraza en medio á la tierra, también esférica y habitada en todo su rededor ${ }^{19}$.

La Edad Media fue en cuestiones astronómicas y geográficas, como en muchos otros aspectos, heredera de la ciencia grecorromana; fruto de su influjo, se mantuvo durante el Medievo la idea de la Tierra esférica. Difícil era sin embargo en esos momentos proyectar gráficamente la tridimensionalidad. Como es bien sabido, la larga Edad Media tuvo que reconquistar la plasmación de la tercera dimensión. Durante los primeros siglos, que engloban la conocida como Alta Edad Media, se acusó una pérdida de técnica respecto de las formulaciones espaciales grecorromanas. Sirva como ejemplo la representación de los elementos geométricos en las Etimologías de san Isidoro (III, 12). El obispo hispalense distinguía entre "figuras sólidas», aquellas "delimitadas por la longitud, la latitud y la altura», es decir, las tridimensionales, y las «figuras planas», encabezadas por «el círculo, que es una figura plana limitada por su circunferencia. Su centro es un punto del que equidistan todos los demás». Al grupo de las primeras pertenece «la esfera», descrita como "una figura de forma redonda igual en todas sus partes $»^{20}$. Las numerosas copias manuscritas

${ }^{17}$ H. Belting, El Bosco. El jardin de las delicias. Madrid, Abada, 2009. 1986, p. 23.

18 C. Kappler, Monstruos, demonios y maravillas a fines de la Edad Media. Madrid, Akal,

19 D. Laercio, Vidas, opiniones y sentencias de los filósofos más ilustres. Valladolid, Maxtor, 2008, p. 132.

20 San Isidoro de Sevilla, Etimologías, edición bilingüe, 2 vols. Madrid, Biblioteca de Autores Cristianos, 1994-2000, vol. 1, p. 437. 


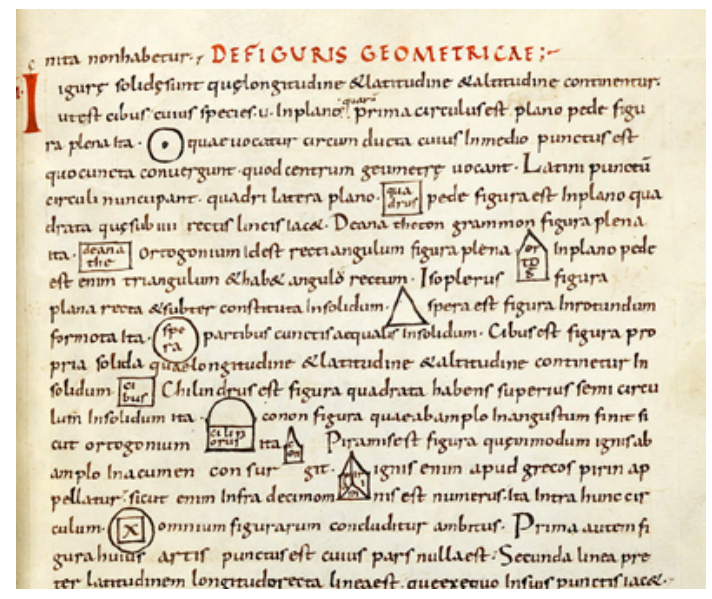

Fig. 10. Isidorus Hispalensis, Etymologiarum sive originum libri; De natura rerum (siglo Ix). Zofingen, Stadtbibliothek (Pa 32, fol. 46r).

de esta obra incorporan dibujos de estas figuras, aunque apenas existen recursos por parte de los escribas o iluminadores para distinguir, en el caso que aquí nos interesa, el círculo de la esfera. Uno de los códices de las Etimologías isidorianas opta por incluir ese punteado central del círculo, para diferenciar la figura plana de la sólida esfera (fig. 10). Sin embargo, si viéramos esta última figura fuera de contexto, careceríamos de argumentos para sostener que se trata de una forma tridimensional. Esto mismo es lo que sucede cuando contemplamos un mapa medieval. Necesitamos, pues, contextualizarlo para su correcta lectura.

Según describía Matfré Ermengaud, «el agua del mar ciñe y cubre la Tierra por todas partes excepto por una [...] muy pequeña», que es la que habitamos. A partir de aquí podemos afirmar, pues, que la Tierra en la Edad Media era más azul que lo que actualmente consideramos nuestro planeta, ya que la proporción de agua era mucho mayor ${ }^{21}$. La ecúmene, es decir, ese espacio habitado y habitable, era muy reducido, y a la hora de cartografiar la Tierra solo se representaba este espacio, junto con el océano que lo circundaba. Los mapas medievales podrían entenderse como la proyección de la tierra del Breviario de amor de Ermengaud vista desde arriba. Aparentemente resultan planos.

Podríamos explicar «la ambigüedad de esta figura» parafraseando a Claude Kappler como el resultado «de la necesidad de representar una superficie terrestre plana, tal como la vivimos cotidianamente, sin pasar por representaciones geométricas abstractas». E incluso dentro de la cartografía medieval encontramos «la

${ }^{21}$ Para este tema véase R. SimeK, "The Shape of the Earth", en Heaven and Earth in the Middle Ages. The Physical World before Colombus, Woodbridge, The Boydell Press, 1996, pp. 24-38. 


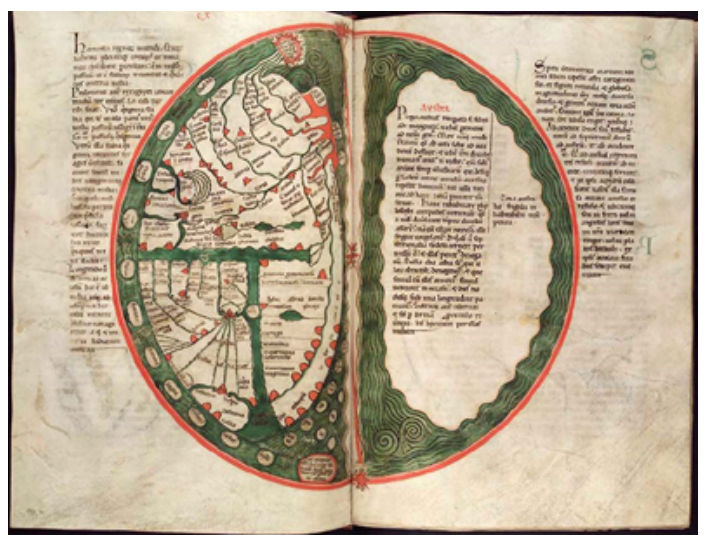

Fig. 11. Lambert de Saint-Omer, Liber floridus (ca. 1180). Herzog-August Bibliothek, Wolfenbüttel (Cod. Gud. Lat. I, fols. 69v-70r).

necesidad también, sin embargo, de dar una idea de la esfericidad del universo", por ejemplo, en un mapamundi del Liber floridus de Lambert de Saint-Omer y en otro del Comentario al Apocalipsis de Beato de Liébana. No obstante, la manera de resolver esa idea de la esfericidad resulta en estos casos más críptica que de la mano -o del pincel- de El Bosco.

El mapamundi del Liber floridus que nos ocupa ahora es el contenido en el códice de la Herzog-August Bibliothek, Wolfenbüttel (Cod. Gud. Lat. I, fols. 69v-70r), de ca. 1180 (fig. 11). Se trata de un mapa de tipo zonal que incluye tanto el hemisferio septentrional -donde se encuentra la parte templada en la que habitamos- como el hemisferio meridional, habitado por los antípodas; un extenso texto descriptivo sobre este territorio así lo afirma: «[...] Hanc inhabitare phylosophi antipodes autumant [...] $»^{22}$, es decir, "[...] Los filósofos afirman que esta zona está habitada por los antípodas [...]». Además de esta destacada presencia de la tierra antípoda, en el extremo sudoccidental de la ecúmene encontramos otro territorio a modo de gran isla habitada por los antípodas: «Hic antipodes nostri habitant sed noctem diversam diesque contrarios perferunt et estatem»" ("Aquí viven nuestros antípodas pero tienen noche distinta y días contrarios y verano»). La repetición de una tierra poblada por antípodas a nuestro oeste, además de su tradicional aparición al sur, ha sido justificada por la dificultad que suponía la representación de la esfericidad del mundo ${ }^{24}$.

22 A. Hiatт, «Blank Spaces on the Earth». The Yale Journal of Criticism, 15:2 (2002), p. 229. Para este mapamundi véase del mismo autor Terra incognita: Mapping the Antipodes Before 1600. Chicago, University of Chicago Press, 2008, pp. 107-109.

23 Ibidem, p. 232.

${ }^{24}$ E. Edson, Mapping Time and Space..., p. 110. 


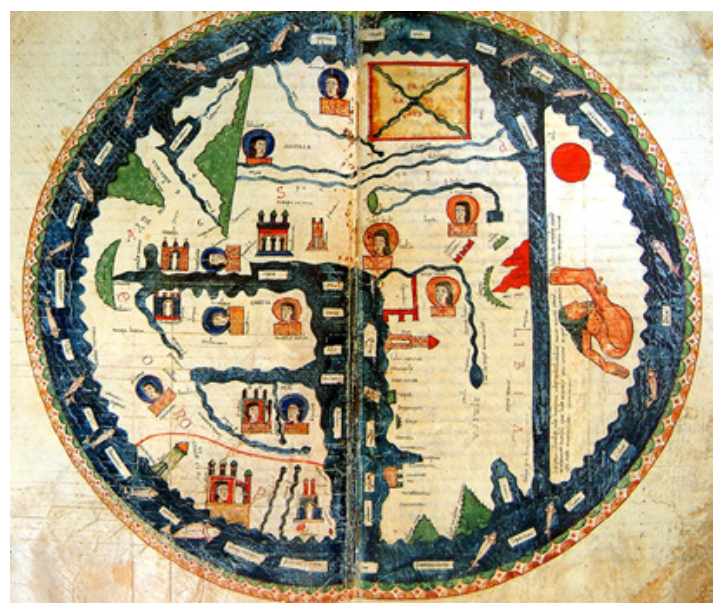

Fig. 12. Beato de El Burgo de Osma (1086). Cabildo de la Catedral de El Burgo de Osma, Soria (Cod. 1, fols. 34v-35r).

Esta misma idea explica la duplicación de otro elemento geográfico en el mapamundi del Beato de El Burgo de Osma (1086) ${ }^{25}$ (fig. 12). Como es usual en el corpus cartográfico de los Beatos, este mapamundi incorpora la isla de "Tile» (Thule), que san Isidoro describía en sus Etimologías (xıv, 6, 4) como «la última isla del océano, entre el norte y el occidente, más allá de Britania. Recibe su nombre del sol, porque en ella efectúa el sol el solsticio de verano, no existiendo día más allá de ella $»^{26}$. Además, distante de ella, figura excepcionalmente en este ejemplar la "Solitio magna», posiblemente la Gran Isla del Solsticio del legendario monje Trezenzonio. Coincidentes en el elemento solar, ambas islas fueron asimiladas con la misma referencia insular por Serafín Moralejo Álvarez, explicando esta duplicidad en distintos lugares para recrear de esta manera la idea de la tridimensionalidad ${ }^{27}$.

Recursos como los anteriores, indudablemente artificiosos, dejaron de ser necesarios una vez que se conquistó la tercera dimensión en la plástica artística y se recuperó en el occidente Europeo la Geografía de Claudio Ptolomeo (siglo in d.C.).

${ }^{25}$ Cabildo de la Catedral de El Burgo de Osma, Soria (cód. 1, fols. 34v-35r). Para los mapas de los Beatos véase S. SÁenz-López Pérez, Los mapas de los Beatos. La revelación del mundo en la Edad Media. Burgos, Siloé, 2014. Este manuscrito fue estudiado en la edición crítica del facsímil: José Arranz et al., El Beato de Osma: estudios. Valencia, Vicent García, 1992.

26 San Isidoro de Sevilla, Etimologías, vol. 2, p. 193.

27 S. Moralejo Álvarez, «Las islas del Sol. Sobre el mapamundi del Beato del Burgo de Osma», en $A$ imagem do mundo na Idade Média. Actas do Colóquio Internacional, Lisboa, Ministério da Educação, 1992, pp. 50-53; reed. en Patrimonio artístico de Galicia y otros estudios. Homenaje al Prof. Dr. Serafin Moralejo Álvarez, 3 vols., Santiago de Compostela, Xunta de Galicia, 2004, vol. 2, pp. 269-270. 
Ambos fenómenos fueron prácticamente simultáneos, y no por $\operatorname{azar}^{28}$. Conocida durante siglos en los mundos islámico y bizantino, la Geografía de Ptolomeo llegó a Florencia hacia 1400 entre las obras manuscritas traídas a esa ciudad desde Constantinopla por el erudito Manuel Ghrysoloras, siendo traducida del griego al latín por Jacopo d'Angiolo hacia 1406-1409. Ptolomeo daba las claves para proyectar la forma esférica de la Tierra sobre la superficie plana del mapa mediante reglas matemáticas. Poco después, en la misma ciudad, Filippo Brunelleschi inventaba un recurso para proyectar lo que conocemos como perspectiva lineal, creando de manera científica la tercera dimensión sobre el soporte pictórico bidimensional ${ }^{29}$. Arte y ciencia conseguían, pues, dar visibilidad a una idea que se arrastraba desde hacía mucho tiempo.

\section{JERUSALÉN ES EL OMBLICUS MUNDI}

Si recurrimos de nuevo a los datos cuantificables, la mayoría de los mapas realizados en la Edad Media no ubican Jerusalén en el centro del mundo. De hecho, son tan solo un puñado de ejemplares los que sí lo hacen: otra vez, la excepción que confirma la regla. Posiblemente la difusión alcanzada por algunas imágenes cartográficas que posicionan Jerusalén en el centro -caso por ejemplo del mapamundi de Hereford (ca. 1300) ${ }^{30}$ (fig. 13) - han contribuido a generalizar la idea de que Jerusalén era el ombligo del mundo. Así lo afirma Philip S. Alexander al comienzo de un trabajo seminal sobre el tema, "Jerusalem has evoked many images but none is perhaps more vivid and abiding than that of the Holy City as the center and navel of the earth $»^{31}$. No obstante, como comenzábamos en nuestra referencia a este otro mito de la Edad Media, los mapas medievales que centran Jerusalén son realmente una anomalía ${ }^{32}$.

${ }_{28}$ Véase S.Y. Edgerton, Jr., «Florentine Interest in Ptolemaic Cartography as Background for Renaissance Painting, Architecture, and the Discovery of America». Journal of the Society of Architectural Historians, 33:4 (1974), pp. 275-292.

${ }_{29}$ Para este tema véase M. Kemp, La ciencia del arte: la óptica en el arte occidental de Brunelleschi a Seurat. Tres Cantos (Madrid), Akal, 2000, pp. 17-23.

${ }^{30}$ Hereford Cathedral, Hereford, Reino Unido.

31 P.S. Alexander, "Jerusalem as the "Omphalos" of the World: On the History of Geographical Concept». Judaism: A Quarterly Journal of Jewish Life and Thought, 46:2 (1997), pp. 147158; y "Jerusalem as the Omphalos of the World: On the History of a Geographic Concept», en L.I. Levine (ed.), Jerusalem: Its Sanctity and Centrality to Judaism, Christianity, and Islam, Nueva York, Continuum, 1999, pp. 104-119.

32 A.-D. von DEN BRINCKEN, «Jerusalem on Medieval Mappaemundi: A Sote Both Historical and Eschatological», en P.D.A. Harvey (ed.), The Hereford World Map: Medieval World Maps and their Context, Londres, British Library, 2006, pp. 355-379; I. BAumgärTner, "Die Wahrnehmung Jerusalems auf mittelalterlichen Weltkarten", en D. BAUER, et al. (eds.), Jerusalem im Hochund Spätmittelalter. Konflikte und Konfliktbewältigung-Vorstellungen und Vergegenwärtigungen, Fráncfort del Meno, Campus, 2001, pp. 271-334; y «Erzählungen kartieren: Jerusalem in mittelalterlichen Kartenräumen», en A. Hoffmann y G. Wolf (eds.), Jerusalem as narrative space, Leiden, Brill, 2012, pp. 231-261. 


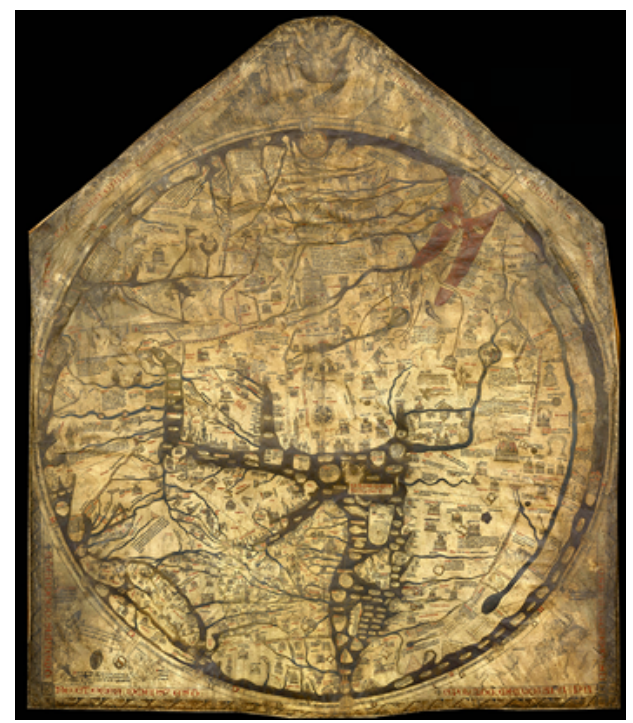

Fig. 13. Mapamundi de Hereford (ca. 1300). Hereford Cathedral, Hereford, Reino Unido.

Los propios textos bíblicos que veíamos anteriormente sirvieron para documentar la planitud del mundo, y sirven también en esta ocasión para revelar la posición central de la ciudad santa. El profeta Ezequiel 5:5 recoge de boca de Dios la siguiente afirmación: «Todo esto se refiere a Jerusalén. La establecí en medio de las naciones, rodeada de países ${ }^{33}$. En el siglo viI, el abad Adomnán de Iona (ca. 624704), siguiendo al obispo galo Arculfo (siglo viI), reafirmaba que había en el centro de Jerusalén una columna muy alta que, durante el solsticio de verano al mediodía, no proyectaba ninguna sombra, lo que explicaba su posición en el centro de la Tierra $^{34}$. Esta columna, levantada por Adriano frente a la puerta de Damasco, está representada en la Jerusalén del mosaico de la iglesia de San Jorge en Madaba, Jordania (siglo vi), un mapa de Tierra Santa que a su vez centra la ciudad sagrada por

33 Sagrada Biblia. Madrid, Biblioteca de Autores Cristianos, 2017, p. 1065.

${ }^{34}$ Adomnán, De locis sanctis, I, 11.1-3. Para una edición de esta obra véase P. Geyer et al., Itineraria et alia geographica: Itineraria Hierosolymitana. Itineraria Romana. Geographica, 2 vols, vol. 1, Corpus Christianorum, Series Latina 175. Turnhout, Brepols, 1965; para literatura sobre esta imagen de Jerusalén, R. Aist, From Topography to Text: the Image of Jerusalem in the Writings of Eucherius, Adomnán and Bede, Studia Traditionis Theologiae 30. Turnhout, Brepols, 2019; y T. O’Loughlin, "Adomnán's plans in the context of his imagining "the most famous city"», en L. Donkin y H. Vorholt (eds.), Imagining Jerusalem in the Medieval West, Proceedings of the British Academy 175, Oxford, Oxford University Press; for the British Academy, 2012, pp. 15-40. 
excelencia ${ }^{35}$. Razones de índole científica se unían a los textos sagrados para justificar esa centralidad. Otras simbólicas -la preeminencia jerárquica que otorga el centro- reforzaron esa posición. Pese a todo, como ya hemos adelantado, la centralidad cartográfica de Jerusalén ocurrió en pocas ocasiones, y, además, todas ellas concentradas en el tiempo y el espacio.

Mapas de origen o influencia inglesa o de la baja Sajonia optaron por esta opción en el siglo XII y después, de nuevo, en el XIV. Al primer grupo pertenecen mapas esquemáticos tripartitos ${ }^{36}$, sobre los que existe un cierto consenso académico a la hora de explicar la centralidad de Jerusalén con motivo de la caída de esta ciudad en manos de los cruzados tras su asedio en 1099. Según Ingrid Baumgärtner, la pérdida de Jerusalén tras el devastador sitio de 1244 reimpulsó de nuevo esa centralidad, lo que justificaría la reubicación de Jerusalén como ombligo del mundo en algunos de los más célebres mapas medievales, como el conocido como Psalter Map (ca. 1265) ${ }^{37}$, sobre el que volveremos más adelante (fig. 25); el ya mencionado mapamundi de Hereford (ca. 1300); o el mapamundi de Ebstorf (ca. 1300), desaparecido en la II Guerra Mundial y del que solo quedan reproducciones facsimilares; así como en otros esquemáticos, tanto un mapa $\mathrm{T}$ en $\mathrm{O}$ contenido en manuscrito misceláneo (siglo XIII) ${ }^{38}$ como un mapa zonal en un manuscrito de contenido histórico de John of Wallingford (Abadía de St. Albans o Wymondham, ca. 1247-1258) ${ }^{39}$ (fig. 14). A través de distintas estrategias se esforzaron los cartógrafos en demostrar esa centralidad: por ejemplo, en este último mapa, el topónimo «Ieru/sa/ le(m)» se fragmenta en tres para ocupar con toda la palabra las tres partes o continentes alrededor del centro del mundo. Los mapas más historiados optaron por decorar gráficamente ese centro. En el caso de Ebstorf se incorporó la escena de la resurrección de Cristo $^{40}$ : Jerusalén adopta un perímetro cuadrado rodeada por una muralla con doce puertas repartidas de forma regular; en su interior figura la imagen de Cristo resucitado, quien, mientras dos soldados duermen, sale del sarcófago enarbolando triunfante la bandera de su victoria sobre la muerte y dirigiéndose hacia Oriente (fig. 15). Esta dirección no es arbitraria, allí se localiza en el mapa el paraíso terre-

35 Para este mapa véase M. Piccirillo y E. Alliata, The Madaba Map Centenary, 18971997: Travelling Through the Byzantine Umayyad Period. Jerusalén, Studium Biblicum Franciscanum, 1999.

${ }^{36}$ El contenido en el compendio de textos homiléticos de la abadía de Saint-Bertin (Francia), Bibliothèque Municipale, Saint-Omer (Ms. 91, fol. 1r); manuscritos de cómputo, como el de la abadía de Thorney (1110), St. John's College, Oxford (Ms. 17, fol. 6r) o de Peterborough (ca. 1120), British Library, Londres (Harley Ms. 3667, fol. 8v), así como el mapa inacabado de la miscelánea eclesiástica inglesa, Wulfstan's Handbook (Worcester, Reino Unido, ca. 1100), Corpus Christi College, Cambridge (Ms. 265, p. 210),

37 British Library, Londres (Add. Ms. 28681, fol. 9r).

38 Trinity College, Dublín (Ms. 367, fol. 83v).

39 British Library, Londres (Cotton Ms. Julius D. viI, fol. 46r).

40 Para este mapa véase H. Kugler, et. al., Die Ebstorfer Weltkarte, 2 vols. Berlín, Akademie Verlag, 2007. 


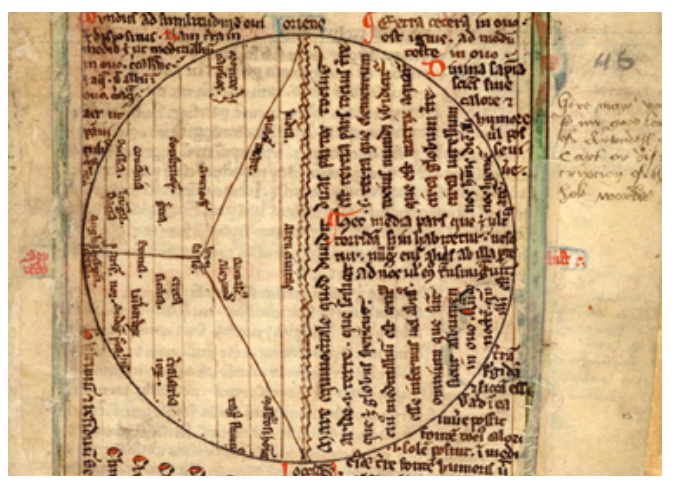

Fig. 14. John of Wallingford, Collectanea (ca. 1247-1258). British Library, Londres (Cotton Julius D.VII, fol. 46r).

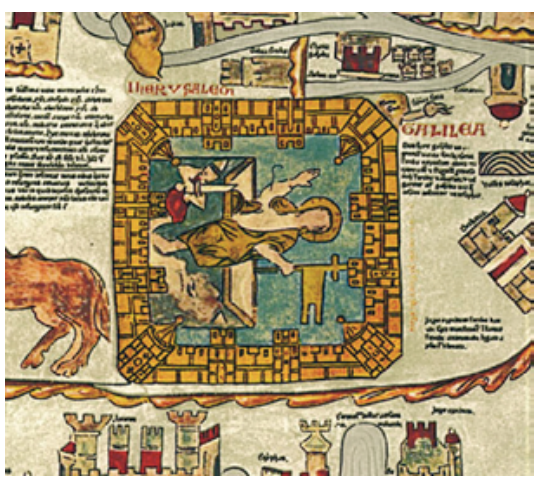

Fig. 15. Detalle del facsímil del mapamundi de Ebstorf (ca. 1300).

nal y allí está también la cabeza de Cristo, pues toda su figura queda embebida en el mapa (manos y pies apuntan hacia los otros puntos cardinales).

Sirva la Jerusalén de Ebstorf para poner de relieve que la imagen de esta ciudad se corresponde más con la celestial que con la terrenal, una idea que podría generalizarse para los mapas que centralizan Jerusalén ${ }^{41}$. Volviendo a su vinculación con las cruzadas, Paul D.A Harvey reconocía que «it is difficult to establish a cause and effect relationship between crusading and map production», pero afirmaba que, en cualquier caso, «the goal of these maps (and medieval maps in general) was not to facilitate travel, but rather to instruct viewers about the "true" nature of the world through carefully constructed presentations of regional geography, history, and ethnography [...]. The primary aim was to incite the viewer to meditate upon the divine ordering of the universe» ${ }^{42}$.

Este uso de mapas como herramienta para la meditación ha sido sugerido por varios investigadores, con Daniel K. Connolly a la cabeza ${ }^{43}$. De hecho, el propio Connolly se refirió a mapas como el de Hereford, así como a los laberintos de las catedrales góticas, como artefactos materiales empleados para facilitar prácticas corporales o mentales que tendrían como destino viajes espirituales a Jerusalén: el

${ }^{41}$ En esta línea véase el trabajo de M. Kupfer, «The Jerusalem Effect: Rethinking the Centre in Medieval World Maps», en Bianca KüHnel et al. (eds.), Visual Constructs of Jerusalem, Cultural Encounters in Late Antiquity and the Middle Ages, Turnhout, Brepols, 2014, pp. 353-365.

42 P.D.A. Harvey, «The Crusaders' Holy Land in Maps», en E. Lapina, et al. (eds.), The Crusades and Visual Culture, Farnham, Ashgate, 2015, pp. 117-130.

43 Desde su tesis doctoral, D.K. Connolly, «Imagined Pilgrimage in Gothic Art: Maps, Manuscripts and Labyrinths», tesis doctoral, University of Chicago, 1998, a publicaciones especialmente en torno a la obra de Matthew Paris, The maps of Matthew Paris: medieval journeys through space, time and liturgy. Woodbridge-Rochester, Boydell Press, 2009. 


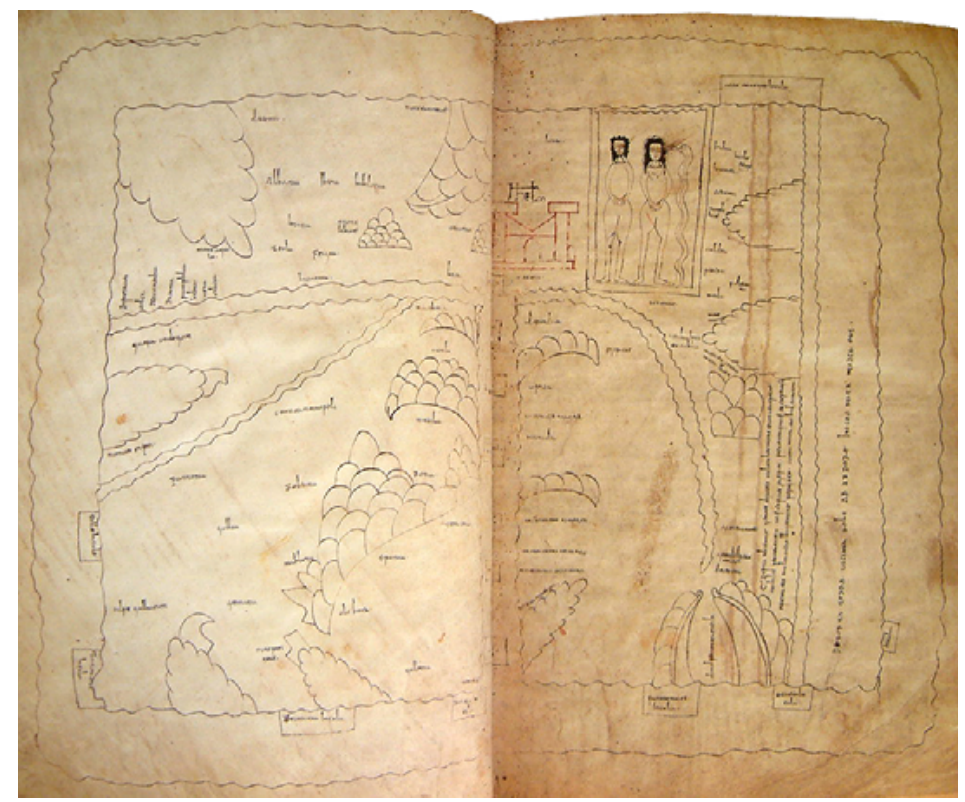

Fig. 16. Beato de Urgel (último cuarto siglo x). Museo Diocesá de La Seu d’Urgell, Lérida (Núm. Inv. 501, fols. viv-virr).

centro de los laberintos góticos simboliza esta ciudad, que en los mapas arriba referidos se convierte en verdadero ombligo del mundo.

Son los menos, insistimos, los que convierten a Jerusalén en ese omphalos. Técnicamente muchos mapas medievales disuaden esta posibilidad cuando se proyectan abarcando dos folios dentro de un códice. En estos casos no hay cabida para una estricta centralidad. Esto no evita, sin embargo, que se resalte la ciudad, que es en cualquier caso un referente -si no $e l$ referente- del orbe cristiano. Pueden señalarse como ejemplo el mapamundi del Beato de Urgel (último cuarto siglo x) ${ }^{44}$, realizado en un cuadernillo que quedó sin policromar (fig. 16). Solo se aprecia, pues, el dibujo cartográfico trazado todo él en tinta negra, salvo Jerusalén, dibujada en rojo; es el único elemento del mapa que figura en este color, lo que pone de relieve que ya desde el principio de la creación del mapamundi la ciudad se concebía para destacar. Mapamundis de otros ejemplares de los Beatos así lo acreditan, como el

${ }_{44}$ Museo Diocesá de La Seu d’Urgell, Lérida (Núm. Inv. 501, fols. viv-virr). Para los mapas de los Beatos véase SÁenz-López Pérez, Los mapas de los Beatos... Este manuscrito fue estudiado en la edición crítica del facsímil: P.K. KLeIn, Beatus de Liébana Codex Urgellensis: comentario a la edición facsímil. Madrid, Testimonio Compañía Editorial, 2002. 


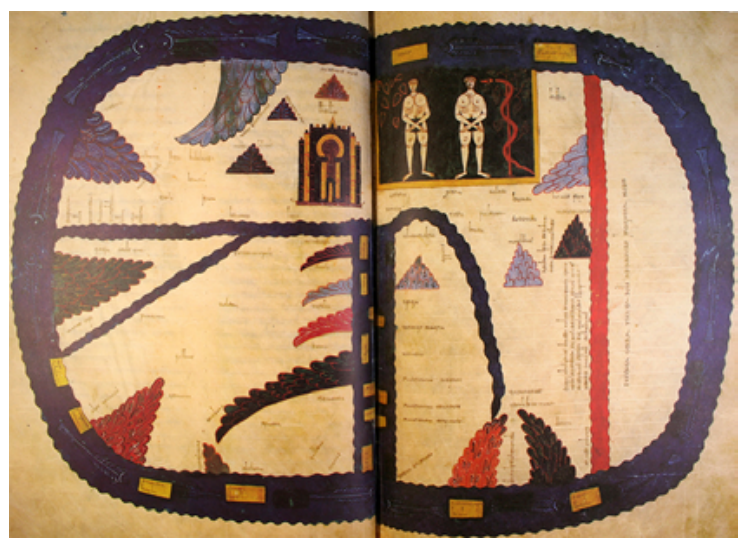

Fig. 17. Beato de Fernando I y doña Sancha (1047). BNE, Madrid (Mss/Vitr. 14-2, fols. 63v-64r).

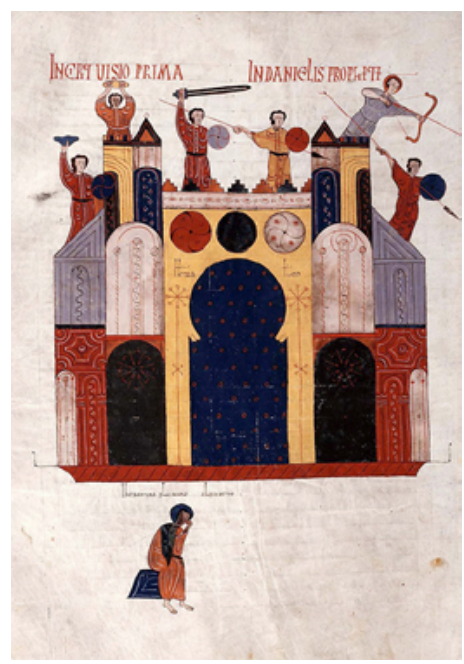

Fig. 18. Beato de Fernando I y doña Sancha (1047). BNE, Madrid (Mss/Vitr. 14-2, fol. 268v).

contenido en el códice de Fernando I y doña Sancha $(1047)^{45}$, donde Jerusalén solo rivaliza visualmente con el paraíso terrenal (fig. 17).

Frente a la céntrica Jerusalén, convertida como decíamos en la celestial, la Jerusalén descentrada, aquella que se localiza donde le corresponde geográficamente, se identifica con la terrena. No en vano, volviendo a los Beatos, debemos señalar que aquellos manuscritos que incorporan la miniatura del asedio de Jerusalén y la lamentación de Jeremías ${ }^{46}$, siguiendo el pasaje de Jeremías 39, muestran una mayor cercanía iconográfica entre esta -véase por ejemplo la del Beato de Fernando I y doña Sancha (fols. 268v-269r) (fig. 18) - y la Jerusalén del mapa, que con la Celestial -que en este mismo códice está en el fol. 253v-.

Muchos otros mapas medievales enfatizan su vertiente terrenal a través del hito más representativo de la urbe cristiana: la presencia allí del Santo Sepulcro. Las ciudades en los mapas medievales son esencialmente convenciones arquitectónicas, alejadas de la verdadera trama urbanística o monumental. Existen sin embargo elementos que acercan a unas u otras a ser identificadas con una ciudad en concreto.

45 BNE, Madrid (Mss/Vitr. 14-2, fols. 63v-64r). Para este manuscrito véase M. Miró BlanCHARD, Beato de Fernando I y Sancha. Barcelona, Moleiro, 2006.

46 Para esta miniatura en los Beatos véase C. Cid PRIEgo, "Las miniaturas del cerco de Jerusalén del Comentario al Libro de Daniel en los códices del Beato». Liño. Revista Anual de Historia del Arte, 7 (1987), pp. 7-38. 


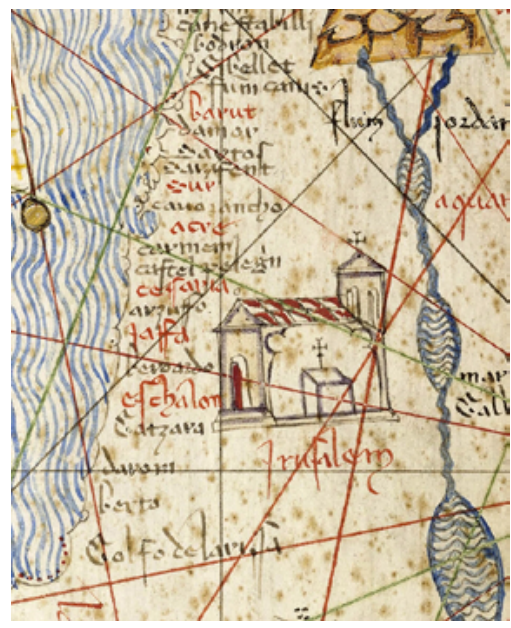

Fig. 19. Detalle del Atlas Catalán (ca. 1375) de Cresques Abraham. Bibliothèque nationale de France, París (Ms. Espagnol 30).

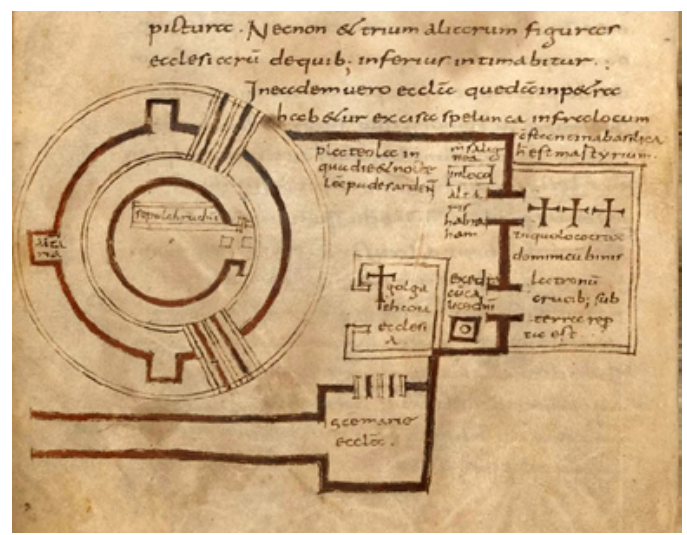

Fig. 20. Adomnán, De locis sanctis (siglos VIII-IX). Bibliothèque nationale de France, París (Ms. Latin 13048, fol. 4r).

La cartografía náutica de la Baja Edad Media ${ }^{47}$ anexionó a la forma basilical con la que se representaba la ciudad de Jerusalén una estructura a modo de arqueta con tapa en talud coronada con una cruz para significarse como monumento que acoge una reliquia (fig. 19). Ni Roma ni Santiago de Compostela -otras urbes simbolizadas mediante el motivo de templete- exhiben esta distinción de la que hace alarde Jerusalén. Asimismo, iconográficamente no es extraño que esta ciudad adopte una sección circular en recuerdo de la Rotonda, cartografiada en manuscritos del $D e$ locis sanctis de Adomnán (fig. 20).

No podemos concluir este repaso por la excepcional localización de Jerusalén en el centro del orbe sin incluir una obra única, aunque nuevamente franqueemos los límites cronológicos de la Edad Media. Se trata del mapa con forma de trébol que Heinrich Bünting (1545-1606), un pastor protestante alemán, introdujo

47 Dentro de la amplia literatura existente sobre la cartografía náutica bajomedieval son imprescindibles los siguientes títulos: T. CAMPBELL, «Portolan Charts from the Late Thirteenth Century to 1500 ", en J.B. Harley y D. Woodward, Cartography in Prehistoric, Ancient, and Medieval Europe and the Mediterranean, vol. 1, The History of Cartography, Chicago, University of Chicago Press, 1987, 371-463; R.J. Pujades I Bataller, Les cartes portolanes. La representació medieval d'una mar solcada. Barcelona, Institut Cartogràfic de Catalunya, 2007; y C. Hofmann, H. Richard y E. VAGNON (eds.), L'Âge d'or des cartes marines. Quand l'Europe découvrait le monde. París, Bibliothèque nationale de France-Seuil, 2012. 


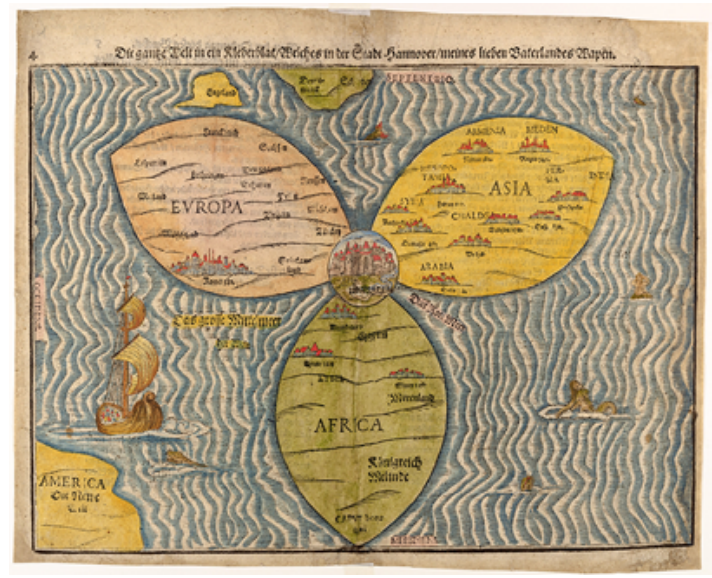

Fig. 21. Heinrich Bünting, Die ganze Welt in einem Kleberblatt welches ist der Stadt Hannover meines lieben Vaterlandes Wapen (Magdeburgo, 1581). Cornell University Library,

Ithaca (1008.01).

en su Itinerarium Sacrae Scripturae ${ }^{48}$. Esta obra, que vio la luz por primera vez en Magdeburgo en 1581 y de la que se realizaron más de sesenta ediciones y múltiples traducciones hasta 1774, ofrecía información geográfica detallada de Tierra Santa extractada del Viejo y el Nuevo Testamento, y estaba ilustrada por mapas igualmente detallados, así como otros de carácter alegórico, como el que es ahora objeto de nuestra atención (fig. 21). Conocido como trébol del mundo, el mapa adapta la Tierra a la forma de esta planta. Los tres foliolos del trébol conforman Europa, África y Asia, y el centro de unión es ocupado por Jerusalén. Según una indicación escrita, el mar Rojo separa África de Asia y el mar Mediterráneo Europa de África. Inglaterra y Escandinavia quedan al margen, a modo de islas, si bien de esta última no se completa su contorno. Lo mismo ocurre en el caso de América, un Nuevo Mundo que se asoma tímidamente en el margen.

El diseño trebolado es indudablemente un homenaje a Hannover, la ciudad natal de Bünting, pues en su escudo de armas recoge este elemento. Así figura en el título del mapa: Die gantze Welt in ein Kleberblat Welches in der Stadt Hannover meines lieben Vaterlandes Wapen, es decir, el mundo entero en una hoja de trébol, como en la ciudad de Hannover, mi querida patria. Asimismo, este formato ha sido asociado con significaciones trinitarias, y enraizado con los mapas tripartitos medievales (fig. 1).

48 Véase H.A.M. Van Der Heijden, «Heinrich Bünting's Itinerarium Sacrae Scripturae, 1581: a chapter in the geography of the Bible». Quaerendo, 28:1 (1998), pp. 49-71. 


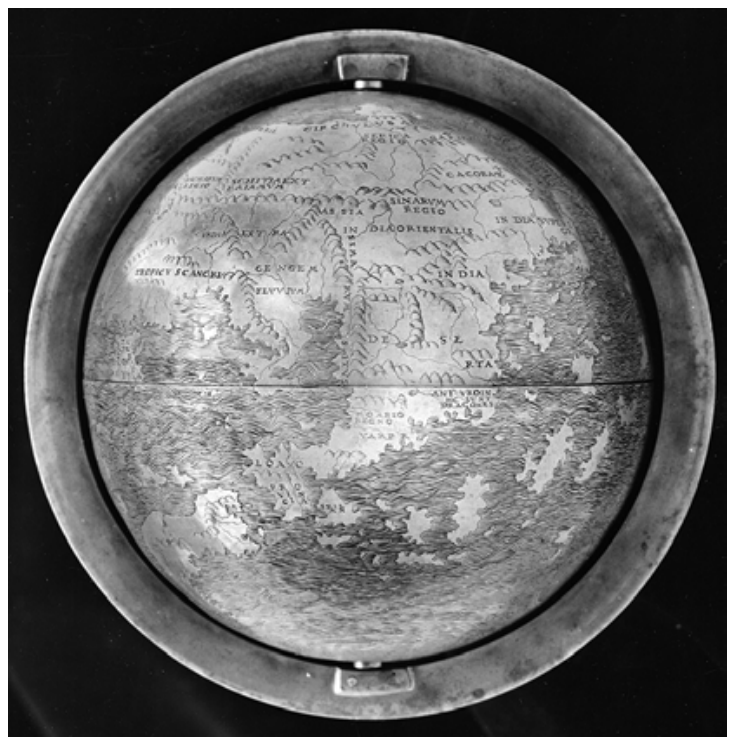

Fig. 22. Globo de Hunt-Lenox (ca. 1510). New York Public Library, Nueva York, Astor, Lenox and Tilden Foundations, Rare Books and Manuscripts.

\section{HIC SUNT DRACONES}

Que los mapas medievales señalaban mediante dragones u otras monstruosidades las zonas desconocidas y la presencia de peligros, e incluso que a todo eso se le daba voz con la frase latina "Aquí hay dragones», es un decir, muy habitual, cuando se describe el mundo de la Edad Media. Pero esto no es así. Claro que hay monstruos e indicaciones de peligros, y que incluso en los mapas medievales encontramos serpientes y dragones, pero la fórmula Hic sunt dracones no está presente en ninguno de ellos; de hecho, no hace su aparición hasta el Globo de Hunt-Lenox (ca. 1510 $)^{49}$ : una pequeña esfera terrestre grabada en cobre, uno de los más antiguos globos terráqueos conservados y el primero en incorporar el Nuevo Mundo (fig. 22). H[I]C SVNT DRACONES figura sin embargo en el viejo mundo, concretamente en la costa oriental de Asia, en la llamada "cola de dragón», una desmesurada prolongación de la península de Indochina presente ya en los mapas de Henricus Martellus

${ }^{49}$ New York Public Library, Nueva York, Astor, Lenox and Tilden Foundations, Rare Books and Manuscripts. Para este globo véase J.M. Massing, «Hunt-Lenox Globe», en J.A. Levenson (ed.), Circa 1492: Art in the Age of Exploration, Washington, D.C., National Gallery of Art; New Haven, Yale University Press, 1991, p. 235. 


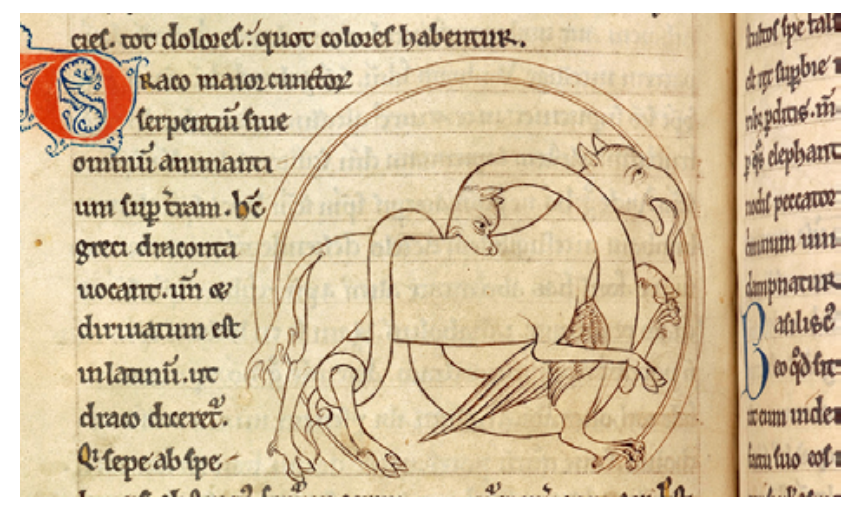

Fig. 23. Bestiario (siglo XII). Cambridge University Library, Cambridge (Ms. Ii.4.26, fol. 46v).

Germanus, cartógrafo que vivió y trabajó en Florencia entre 1480 y $1496^{50}$. Tampoco, con posterioridad a este globo, la frase se generalizó como recurso cartográfico.

Contextualizar los dragones en la Edad Media exige recurrir a los bestiarios. Tradicionalmente esta literatura -a medio camino entre la historia natural animal y la lección moral cristiana- asoció la fuerza del dragón, concretamente de su larga cola, a su capacidad de vencer a toda bestia, incluidos los elefantes, con los que era común que el dragón se representara (fig. 23). Iconográficamente es difícil diferenciarlos de las serpientes o basiliscos, pues todas estas alimañas parecen descender de una idea común. Los bestiarios describen al dragón como «el mayor de todas las serpientes» y están tan asociados a la idea del mal que se añade que «el demonio, que es el más enorme de todos los reptiles, es como este dragón " $^{51}$. Dragones, serpientes y basiliscos están presentes en los mapas, generalmente en los márgenes del mundo. Es el caso, por ejemplo, de la carta náutica genovesa de Angelino Dalorto $(1330)^{52}$, donde junto al cauce del río Nilo se dice «Hic abitante dracones, serpentes, basilischos et etiam diuersis homines et multe allie diuerse bestie oribiles» ("Aquí habitan dragones, serpientes, basiliscos y también hombres diferentes y muchas otras distintas bestias horribles»). Siguiendo esta misma leyenda, la carta veneciana de los hermanos Pizzigani (1367) ${ }^{53}$ incluía en estas aguas dos de estos animales, y en el mismo emplazamiento, pero con anterioridad, el mapamundi de Henry de

${ }^{50}$ Para este cartógrafo véase E. Edson, The world map, 1300-1492: the persistence of tradition and transformation. Baltimore-Londres, Johns Hopkins University Press, 2007, pp. 215-219.

51 I. Malaxecheverría, Bestiario medieval. Madrid, Siruela, 2002, p. 223.

52 Archivio Corsini, Florencia.

53 Biblioteca Palatina, Parma (Ms. 1612). 


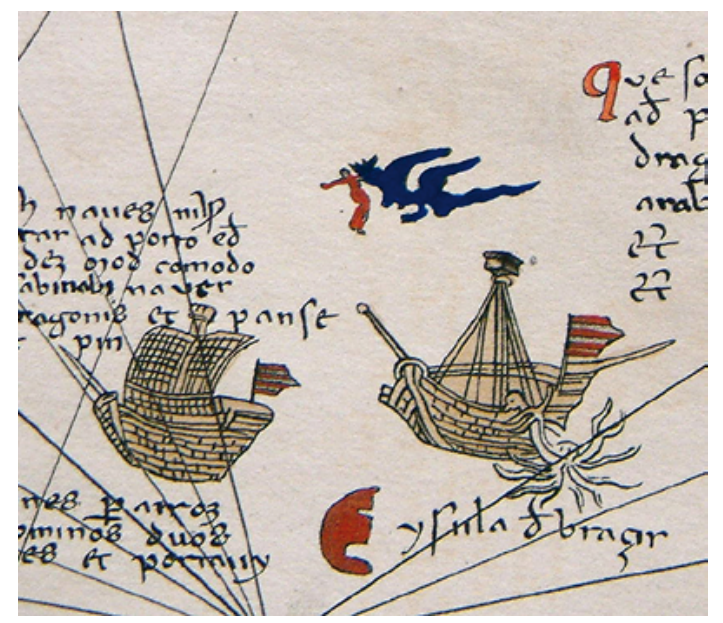

Fig. 24. Detalle de la carta de los hermanos Pizzigani según facsímil de Edme-François Jomard (1367). Biblioteca Palatina, Parma (Ms. 1612).

Mainz (ca. 1190) $)^{54}$ ilustraba un «Basiliscus». Los dragones, pues, sí habitan la ecúmene medieval y, consecuentemente, también los mapas. Para una representación cartográfica aún más sugerente debemos volver a la carta de los hermanos Pizzigani, donde en otro extremo, en este caso el Atlántico, figuran dos leyendas que, de manera muy semejante, describen el ataque de embarcaciones por peligrosos pulpos y dragones; estos últimos, según se dice, se llevan por los aires a los marinos ${ }^{55}$. Los textos se ilustran con la representación de dos naves surcando tan lejanas aguas; una de las embarcaciones está siendo abordada por un pulpo, mientras que un dragón se lleva en vuelo por los aires a una desgraciada víctima (fig. 24). La escena está emplazada casi en el extremo más occidental cartografiado; indudablemente, los dragones vuelven a ocupar los límites del mundo.

Hasta aquí lo dicho, nada parecería desmentir esa idea asimilada al Hic sunt dracones con la que comenzábamos este tercer mito de la Edad Media. Pero la verdad es que dragones, serpientes y basiliscos son solo una de las muchas «animalia monstruosa» que pueblan los mapas, y ni siquiera de las más comunes. No merecen, pues, ostentar ningún protagonismo al respecto. Volvamos al río Nilo para dar cuenta

54 Corpus Christi College, Cambridge (Ms. 66, p. 2). Para este y otros mapas relacionados véase P.D.A. Harvey, «The Sawley Map and Other World Maps in Twelfth-Century England». Imago Mundi. The International Journal for the History of Cartography, 49 (1997), pp. 33-42.

55 Para la transcripción de estas leyendas véase M. Longhena, «La carta dei Pizigano del 1367 (posseduta dalla Biblioteca Palatina di Parma)». Archivio Storico per le Province Parmensi, 5 (1953), p. 58. 




Fig. 25. Psalter Map (ca. 1265). British Library,

Londres (Add. Ms. 28681, fol. 9r).

de ello. El intermitente recorrido de sus aguas y su recóndito nacimiento forjó su leyenda desde la Antigüedad clásica. La Edad Media heredó su mítica hidrografía, especialmente a través de la descripción del mundo contenida en las Historias contra los paganos de Paulo Orosio (ca. 380-ca. 420), quien afirmaba: «Un río de este tipo, que tiene tal nacimiento y tal recorrido [...], en verdad, engendra todos los monstruos que se han atribuido al Nilo" ${ }^{56}$. Numerosos mapas medievales evocan la fecunda monstruosidad de sus aguas, tanto textual como gráficamente. Sirvan como ejemplo los catálogos de monstruosidades desplegados en el mapamundi de Hereford (ca. 1300), así como en el Psalter map (ca. 1265) (fig. 25). Estos mapas exhiben todo un elenco de las llamadas razas monstruosas de Plinio - por ser su Historia natural la obra que consolidó e impulsó la existencia de estas criaturas originadas desde la Grecia clásica-y los dragones apenas tienen importancia ${ }^{57}$.

56 P. Orosio, Historias. Madrid, Editorial Gredos, 1982, pp. 89-90.

57 Dentro de la prolífica bibliografía vertida sobre la monstruosidad en la Edad Media véase R. WittKower, «Marvels of the East. A Study in the History of Monsters», Journal of the Warburg and Courtauld Institutes, 5 (1942), pp. 159-196, un clásico aún de vigente actualidad, o el monográfico de J.B. Friedman, The Monstrous Races in Medieval Art and Thought. Cambridge, MA, Harvard University Press, 2001), con reediciones posteriores como Syracuse, Syracuse University Press, 2000. Más recientemente, las publicaciones de A.S. Mittmann, como la coedición con P. Dendle, Research Companion to Monsters and the Monstrous. Routledge, Ashgate, 2012, especialmente dentro de esta publicación, el trabajo de C. Van Duzer, "Hic sunt dracones: The Geography and Cartography of Monsters", pp. 387-435. 
Más aún, ni monstruos ni dragones son indicadores de lugares desconocidos o peligrosos. Pueden ocupar regiones que no o apenas habían sido exploradas, y que se revestían de peligrosidad, pero en ningún caso deben verse como hitos geográficos cargados de esa connotación. Obviamente los lugares más desconocidos, aquellos de los que apenas se tenían nociones sobre su orografía o hidrografía o del nombre de sus poblaciones, exhibían espacios en blanco susceptibles de ser cubiertos por monstruos y otras exoticidades que siempre han divertido a todo tipo de espectadores. Generalmente estos espacios coincidían con los extremos del mundo, es decir, con los márgenes de los mapas, convertidos en el escenario predilecto del elemento fantástico. Pero es importante señalar que pese a los calificativos que nosotros desde nuestro siglo XXI les impongamos, en la Edad Media los monstruos -también los dragones- formaban parte real del mundo, tal como Evelyn Edson se ha esforzado en reivindicar ${ }^{58}$. No solo se creía en ellos, especialmente desde que san Agustín de Hipona (354-430) los aceptara como parte de la creación divina en La ciudad de Dios (16: 8), sino que integraban y eran fruto de la diversidad que caracterizaba el mundo natural. No en vano, ocupaban un lugar en la Tierra, pues toda literatura teratológica que se precie se afanaba en ubicarlos en un lugar concreto.

El escritor griego Ctesias de Cnido (siglo v a.C.) localizó en la India seres como pigmeos, de pequeña estatura en eterna lucha con las grullas; cinocéfalos, con cabeza de perro que se comunican por ladridos; blemmyae, acéfalos, con los rasgos faciales en el pecho; gigantes o gentes de extraordinaria altura; etc. La India perduró durante mucho tiempo como la cuna de la mirabilia por excelencia, si bien, a medida que el mundo ensanchó sus horizontes, la monstruosidad comenzó a desplazarse. La tórrida África en manos sarracenas y las frías aguas del Atlántico norte fueron otros escenarios privilegiados en el Medievo. También lo fue América una vez que el Mundus Novus se incorporó al teatro del mundo. La monstruosidad originaria en la Grecia clásica, y la que se multiplicó con el devenir de los siglos, peregrinó por estos espacios. De hecho, pigmeos, cinocéfalos, blemmyae y gigantes viajaron por el orbe hasta ser localizados en territorio americano ${ }^{59}$. El cartógrafo francés Pierre Desceliers ubicó a los pigmeos en Canadá en su mapamundi de $1550^{60}$ (fig. 26); Cristóbal Colón conoció la existencia de los cinocéfalos caníbales en el archipiélago caribeño, tal como describió el 4 de noviembre de 1492 en su diario, editado por Fray Bartolomé de las Casas: «Entendió también que lexos de allí avía hombres de un ojo y otros con hoçicos de perros que comían los hombres, y que en tomando uno lo degollavan y le

58 E. Edson, «Mapping the Middle Ages: The Imaginary and the Real Universe of the Mappaemundi", en L. SondergaArd y R.T. Hansen (eds.), Monsters, Marvels, and Miracles: Imaginary Journeys and Landscapes in the Middle Ages, Odense, University of Southern Denmark, 2005, pp. 11-25.

59 Véase S. Davies, Renaissance Ethnography and the Invention of the Human: New Worlds, Maps and Monsters. Cambridge, Cambridge University Press, 2016.

${ }_{60}$ British Library, Londres (Add. Ms. 24065). Para este mapa véase C. VAn Duzer, The World for a King: Pierre Desceliers' Map of 1550. Londres, The British Library, 2015. 


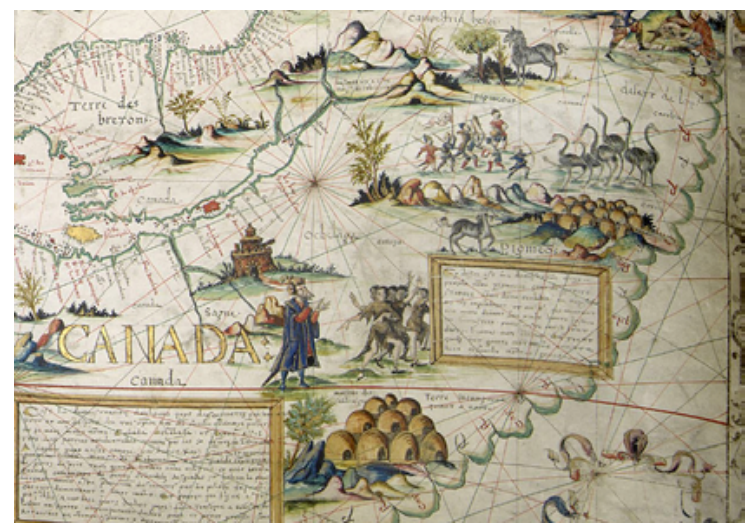

Fig. 26. Detalle del mapamundi de Pierre Desceliers (1550). British Library, Londres (Add. Ms. 24065).

bevían la sangre y le cortavan su natura» ${ }^{61}$. Sir Walter Raleigh, un corsario inglés que durante el siglo XVI realizó varias expediciones a la Guayana en busca de El Dorado, escribió un relato de sus viajes ${ }^{62}$ estando retenido en la Torre de Londres, en el que incluyó la existencia de una tribu de hombres llamada "Ewaipanoma», de los que decía: «They are reported to have their eyes in their shoulders, and their mouths in the middle of their breasts, and that a long train of hair groweth backward between their shoulders» ${ }^{63}$, acercándolos a los blemmyae de los que habían hablado autores como Jean de Mandeville. Finalmente, respecto a los gigantes, no podemos olvidar a los patagones que encontrara la expedición de Fernando de Magallanes al cruzar el estrecho que lleva su nombre: fue en 1520, en la bahía de San Julián (Argentina), cuando según relata el cronista de la expedición Antonio Pigafetta conocieron a «un hombre de estatura gigantesca [...]. Este hombre era tan alto que con la cabeza apenas le llegábamos a la cintura» ${ }^{64}$.

Este viaje de los monstruos nos ha llevado a América, donde tampoco fueron significativos los dragones, como ya veíamos por su ausencia en este territorio

${ }^{61}$ C. Varela (ed.), Cristóbal Colón. Textos y documentos completos. Madrid, Alianza Editorial, 1992, p. 131.

62 W. RALEIGH, The discouerie of the large, rich, and bevvtiful empyre of Guiana, with a relation of the great and golden citie of Manoa (which the Spanyards call El Dorado) and of the prouinces of Emeria, Arromaia, Amapaia, and other countries, with their riuers, adioyning. Performed in the yeare 1595. Londres, Robert Robinson, 1596.

${ }^{63}$ Voyages and Travels: Ancient and Modern, vol. xxxiII, The Harvard Classics. Nueva York, P.F. Collier \& Son, 1909-1914, n. ${ }^{\circ} 66$.

${ }^{64}$ A. Pigafetta, Primer viaje en torno del globo. Buenos Aires, Editorial Francisco de Aguirre, 1970, p. 21. 
en el Globo de Hunt-Lenox (ca. 1510) (fig. 22). Una vez aquí, en el Nuevo Mundo, volvemos a franquear los límites cronológicos de nuestro foco de atención, la Edad Media. Llegados a este punto debemos poner fin a nuestro acercamiento a tres construcciones mitológicas de esta fascinante época, con la esperanza de haber contribuido, con este humilde trabajo, a que sea un poco más luminosa.

RECIBIDO: 27-04-2020; ACEPTADO: 24-08-2020 